\title{
How An Inventory Cost Misinterpretation Led To Chaos For Purchasing And Operations In A LEAN System
}

Jonathan M. Furdek, Purdue University Calumet, USA

\begin{abstract}
A firm engaging in lean production has employed a computer system to revise order quantities and lot sizes in real time. What appears to be a minor misinterpretation of costs leads to radical fluctuations in inventory and efficiency. Volumes of resources and products grow, contrary to the intent of the system and drastic action is taken to reduce costs, leading to a period of shortages and high administrative costs.
\end{abstract}

Keywords: Inventory, Lean Production

\section{CASE DESCRIPTION}

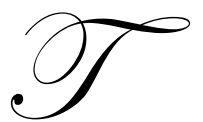

he primary focus of this case is the implementation of a lean production system for a firm committed to a supply chain management strategy. However, the misapplication of the classical EOQ model results in peculiar inefficiencies. The case is appropriate for upper level business or management students, it is designed for approximately one class hour and it requires approximately four hours of preparation by students.

\section{CASE SYNOPSIS}

This firm (real name undisclosed) was under significant cost pressures because of changing patterns of demand, largely due to expanded internet sales. This firm provides a wide range of industrial products primarily through catalog sales. Striving to be competitive, the firm invests in an enterprise resource planning (ERP) system that promises to provide timely control of inventories by adjusting order quantities in real time as costs and demand change. The misinterpretation of the classical EOQ model for determining order quantities results in catastrophic inefficiencies and the remedies are equally disastrous.

\section{INTRODUCTION}

MP America is a major competitor in the industrial supply industry. The company was established in 1928 selling electrical motors, pumps and accessories through catalog sales. With a reputation for prompt delivery, competitive prices and high quality, the firm grew rapidly in sales and in its product line. In 1939, the company opened a second facility and eventually organized its operations into a network of twelve regional distribution centers. The company expanded its product line to include over 300,000 products. In 1981, MP, which had offices in Mexico and Canada, expanded its operations to India and China, creating MP International and hence distinguishing MP America for its domestic network of operations.

The company has a reputation for providing quick turnaround on orders received through its extensive catalog of supplies, office materials, and sundry items and at competitive prices. The firm introduced a B-to-B internet site in 1996 and that part of the business has grown rapidly. Orders are received in written form via mail, over the telephone, by e-mail, or electronically over the website. The moment an order is received it is logged into the data base system, transmitted to a regional distribution center and simultaneously to the logistics carrier. A 
delivery date is established and confirmed with the customer. When the order is prepared for shipping, the order is picked up for delivery by one of the major logistics carriers and billing takes place the instant the order is handed over to the carrier.

In the Chicagoland distribution center, the orders are picked and assembled partly by hand and partly by computer controlled robots. The order is assembled, packaged and sent to transportation all in a matter of hours. Rarely will an order not be filled and shipped on the same day it is received. This requires a great deal of coordination between operations and purchasing to avoid stock outs and delays. Generally, this system has worked well in the past. As orders were pulled and inventories of specific items depleted, operations would submit orders to purchasing. Since inventory information is shared in real time with vendors, purchasing would respond in a timely fashion to replenish stocks and delays in ordering and replenishing stocks were rare. The past success of the Chicagoland center is partly due to the close working relationship between the operations manager and the purchasing manager. They met without fail every week to discuss ways to improve the overall operations of the company.

The success of the B-to-B business over the internet has created an interesting challenge for the organization. The average number of items per order as steadily declined as the B-to-B demand has increased. By 2000 , the average number of items per order was 6.27 and by 2007, the average number of items per order had declined to 4.85. Even though demand and the cost of filling an order had remained relatively stable, there were more orders to be filled per week and the company experienced a significant profit squeeze. Customer expectations of prompt delivery imposed an added pressure on the distribution center.

In response, the corporate operations officer, a recent graduate of a prominent Ivy league MBA program, implemented a new smart decision support system called Rapid Response Operating System, or RROS. One aspect of RROS is that it tracks important demand, lead time and cost parameters, adjusts important operating parameters such as lead time and order quantities and transmits this information to purchasing and to operations in real time. Order quantities are adjusted on a weekly basis and promised delivery dates are transmitted to operations.

\section{THE JANUARY MEETING}

Now that RROS had been implemented, the purchasing manager and the operations manager met with the corporate operations officer to explore the changes that were occurring as a consequence of RROS. Purchasing found, surprisingly, that order quantities appeared to be increasing under RROS rather than decreasing as was anticipated in a lean system. It was explained that these changes were largely the result of adjustments made after an evaluation of orders, lead times and costs. The purchasing department had three employees. The salaries, benefits, along with allocated overhead and utility expenses resulted in an annual fixed cost of $\$ 180,000$. Processing approximately 5,000 orders per year, the average fixed cost per order was $\$ 36.00$. The incremental costs of ordering were $\$ 2.00$ per order, so the average cost of placing an order was $\$ 38.00$. Amortizing these costs over all the orders was perceived to be more efficient. As an example, the distribution center sells approximately 4,000 boxes of the MP929B black ink stick pens per year. With holding costs of $\$ 2.00$ per year and order costs of $\$ 38.00$ per order, the ideal order quantity turns out to be 390 boxes. As a result of these kinds of refinements, larger order quantities were gradually filtering into purchasing. This new system was taking a little pressure off the purchasing department providing purchasing with time to work more closely with vendors. This was welcomed by purchasing. Operations appeared to run smoothly with RROS but had a few minor problems with inventory. Since the lean system limits space for inventory, there was simply not enough space in the bins for the increased volume of some of these orders. Since the robots are programmed to pick items from specific spots, operations could not shift things around. So, extra items were held as a secondary inventory momentarily until operations could reallocate bin spaces and reprogram the robots.

\section{THE FEBRUARY MEETING}

Tracking the MP929B pens, purchasing found that RROS had increased the order quantity from 390 to 410 . It was explained that the efficiencies of RROS were beginning to bear fruit. With more efficient quantities across the board, purchasing was now processing approximately $10 \%$ fewer orders per month. The RROS system 
responded by adjusting quantities to changing costs and one cost that had changed was the average order cost. With fewer orders per month the average fixed cost per order was adjusted to $\$ 40.00$ per order. With the $\$ 2.00$ incremental costs, the average cost of ordering was adjusted to $\$ 42.00$ and consequently the order quantity was automatically adjusted. RROS was doing what it was supposed to do, by quickly adjusting to changing costs and conditions. The operations area was experiencing some significant new problems, however. With a secondary inventory stashed in a variety of places, it became difficult tracking and handling inventories. Productivity was being affected and order lateness was climbing. Re-programming the robots and re-assigning bin space was a priority.

\section{TWO MONTHS LATER}

From the standpoint of purchasing, things had never been better. There had been no delays in placing orders and tracking orders with vendors and logistics providers was better than ever. However, it was noted that the MP929B's order quantity had increased again, to an order quantity of 460. Since orders were larger and less frequent, purchasing was placing fewer orders, so the average cost of placing an order went up and the quantities were increased to compensate. Problems were beginning to appear in operations. The number of late orders was escalating, the number of orders filled per day was declining, and costs, particularly overtime costs, were increasing. Changing the system to allow for the larger bin quantities was a formidable project, so operations focused on developing a secondary inventory system to handle the volumes, but space and manpower were problematic. These inefficiencies were attributed to the adjustment to the new system and perceived to be momentary.

\section{THE NEXT MONTH}

The new chief operating officer had been doing a little investigating. The firm had been losing money and possibly customers for the past few months and intended to get costs under control by scaling back and cutting costs. Part of the cost reduction effort resulted in the furlough of one employee in purchasing. Purchasing was not surprised. Purchasing had plenty of time to get work done, now that they ordered in larger quantities.

\section{MONTH SIX}

The effects of the drastic cost reductions were immediate. With the cut in overhead cost, RROS was cutting the size of orders, keeping purchasing busy. For example, the MP929B's last month were ordered 460 at a time and the RROS system responded to the change in overhead by adjusting the order quantity to 370 . Since the firm was still selling around 4,000 MP929B's per year, with overhead reduced to $\$ 130,000$, the order quantity was reduced. Some elements were improving in operations. Inventory had been cleared out and order processing was running much better. It appeared that the cost cutting was the remedy.

\section{MONTH SEVEN}

Purchasing was stressed. As the order quantities declined, purchasing was processing more orders per month. Purchasing could barely keep up with the workload and couldn't respond to vendors and logistic providers in a timely way. The RROS required purchasing to process orders at a pace of 4,700 per year, which resulted in an average fixed cost of $\$ 27.00$. Along with the $\$ 2.00$ incremental cost per order, RROS had established an order cost of $\$ 29.00$. With no change in demand and holding costs, this resulted in an order quantity of 340 units for the MP929B. But otherwise, operations seemed to be running reasonably well.

\section{MONTH EIGHT}

Purchasing activity had increased nearly $18 \%$ and purchasing had difficulty keeping up with the orders. Purchasing had no alternative but to work overtime and would soon begin working weekends just to handle the backlog. Operations complained that the inability of purchasing to respond and replenish inventories resulted in orders being sent through partially filled because of stock outs of various items. The firm hadn't experienced problems like this before and had a lot of angry customers. It was evident that purchasing needed to recall the furloughed employee as soon as possible. Recalling staff resulted in an overhead increase. And the entire cycle began again. 


\section{DISCUSSION QUESTIONS}

This case is appropriate for a one hour class session. Students are asked to prepare a flow diagram of the supply chain before coming to class which provides a focus for a discussion regarding the potential failure points in the system and possible remedies. The discussion progresses with the following questions:

1. Discuss the appropriateness of using the standard economic order quantity model in this situation.

2. What does the purchasing manager expect will happen work to the number of orders in purchasing, the order quantities, and the inventories in operations when employees that were laid off are called back?

3. Clearly, this is not the way the system should work. What went wrong? What is the one critical error that was made?

Students recognize the misinterpreted cost when they attempt to apply the EOQ model for the data given for the MP929B product. Using the average cost per order, they will obtain the order quantities generated by the RROS system. Quite often students, and also practitioners, have little concern over cost inaccuracies when applying the EOQ model, likely assuming the factors applied in the model are rough estimates, anyway. However, students quickly recognize the implications of an incorrect cost in a dynamic system such as this.

\section{AUTHOR INFORMATION}

Jonathan Furdek is an associate professor in the School of Management at Purdue University Calumet. He is a graduate of Marquette University earning a B.S. in Mathematics and Economics, and a M.S. in Economics. He earned his Ph.D. in Industrial Economics from the Krannert School of Management, Purdue University. His teaching and research interests are in Operations Management and Business Statistics. He resides in Munster, Indiana with his wife, Linda.

\section{REFERENCES}

1. Chopra, S. and P. Meindl. (2007). Supply Chain Management, Strategy, Planning and Operation. $3^{\text {rd }}$ Edition, Pearson/Prentice Hall, Upper Saddle River, NJ.

2. Cooper, M.C., Lambert, D.M., and Pagh, J. (1997). "Supply Chain Management: More than a New Name for Logistics". International Journal of Logistics Management. Vol. 8, No. 1, pp 1-14.

3. Lambert, Douglas M. (2008). Supply Chain Management: Processes, Partnerships, Performance. $3^{\text {rd }}$ Edition.

4. Mentzer, J.T. et al. (2001). "Defining Supply Chain Management”. Journal of Business Logistics. Vol. 22. No. 2. Pp 1-25.

5. Simchi-Levi, D., P. Kaminsky, and E. Simchi-Levi. (2008). Designing and Managing Supply Chains: Concepts, Strategies and Case Studies. $3^{\text {rd }}$ Edition. McGraw-Hill/Irwin. New York. 